\title{
Os historiadores e os acervos documentais e museológicos: novos espaços de atuação profissional
}

Benito Bisso Schmidt

Resumo: 0 texto refleteso brea abertura denovos espaços de atuação profissional ao historiador em instituições como museus, arquivos, centros de cultura ememoriais, buscando examinar o contexto em que se insere tal processo - marcado pela larga difusão de uma cultura da memória - , bem como os desafios ligados a este exercício no que diz respeito à formação, à prática profissional e ao papel da A N PUH como entidade representativa dos historiadores.

Palavras-chave: Profissão de historiador. Lugares dememória. AN PUH . A rquivos. Museus

V ivemos em uma sociedade "seduzida pela memória" (HUY SSE N , 2000), marcada por uma intensa e ansiosa busca de raízes e identidades (HARTOG, 1997, p. 15), na qual o presente logo se aloja em lugares físicos, virtuais e afetivos de memória (N O RA, 1993). Vivenciei esta experiência faz pouco tempo ao me deparar, em uma livraria, com o A Imanaque A nos 90, do jornalista Silvio

* Presidente da A N PUH -RS (gestão 2006-2008). Professor do D epartamento e do PPG em H istória daU FRG S. D iretor do M emorial da Justiça do Trabalho no Rio G rande do Sul. E-mail: bbissos@yahoo.com 
Os historiadores e os acervos documentais e museológicos...

Essinger (2008), no qual pude encontrar alguns fatos e personagens que fazem (ou faziam até aquele momento) parte do meu imaginário presente: a série A rquivo X, o filme Titanic, o apelido "Bráulio", dado a certa parte da anatomia masculina, 0 gol de barriga de Renato $\mathrm{G}$ aúcho pelo Fluminense que decidiu o campeonado carioca. Congelados nas páginas deste livro, lugar de memória de uma geração, tais acontecimentos transmutavam-se em referências nostálgicas, como se eu estivesse folheando um daqueles belos álbuns de fotografias de M arc Ferrez que retratam o Rio de Janeiro no final do século XIX. M inha vida - pensei eu - estava imortalizada, mas, de certa forma, virara peça de museu.

Diante de um mundo que se transforma rapidamente, com fluxos que se comprimem em redes cada vez mais densas de espaço e tempo, buscamos avidamente algumas "ancoragens" (H uyssen, 2000 , p. 34) na tentativa de estancar o tempo e evitar que o passado se perca. D e certa forma, em uma encarnação coletiva do personagem Funes, de Borges (1970), temos o desejo de tudo guardar, de conservar todas as fotos e documentos, de entrevistar todos os velhinhos antes que eles morram, de nada esquecer. A ampliação inimaginável da capacidade de armazenar informações convive, paradoxalmente, com um enorme medo da amnésia.

U m sintoma dessa conjuntura - em que a memória se tornou uma preocupação social, cultural e política central - é a constituição de espaços institucionais de preservação e de celebração dos vestígios do passado (e aqui invoco o título do nosso encontro estadual): museus, arquivos, bibliotecas, centros de documentação, memoriais, rotas turísticas "nostálgicas" ... Um número significativo de órgãos públicos e de instituições privadas, como hospitais, clubes de futebol, empresas e sindicatos, passou a investir na constituição de espaços para a exibição (ou, mais propriamente, para a construção) do passado, para a exposição de certas narrativas a respeito "do que fomos", visando a solidificar uma determinada imagem "do que somos". Sem dúvida, a espetacularização do passado se tornou uma excelente 
estratégia de mark eting, uma forma bastante eficaz de vender imagens, produtos e serviços.

Tais espaços, por um lado, ampliam o âmbito de atuação dos profissionais tradicionalmente voltados à organização, análise e publicização destes "vestígios do passado" - como arquivistas, museólogos e historiadores - além de incorporar outros que normalmente eram mais associados ao presente - como jornalistas, publicitários e arquitetos; entretanto, por outro lado, também criam novos desafios e responsabilidades que não podem ser negligenciados por nenhum destes agentes. Q uero abordar, nesta apresentação, de forma muito sintética, alguns destes desafios e responsabilidades relativos especificamente à atuação do historiador, com atenção especial às questões atinentes à sua formação, à sua prática nestes novos espaços de atuação profissional e às tarefas que a AN PUH - como entidade representativa dos profissionais de história - deve assumir diante deste quadro.

Q uanto à formação, observamos, nos cursos de graduação em H istória, cada vez mais, a criação de disciplinas voltadas à atuação do historiador nos espaços de guarda, organização e publicização do patrimônio histórico-documental, tanto na forma de cursos teóricos, quanto de estágios curriculares. Iniciativas como essas são extremamente bem-vindas, pois possibilitam ao estudante um primeiro contato com instituições como arquivos e museus, suas formas de organização, técnicas de conservação e restauro, elaboração de instrumentos de busca, atendimento ao público, educação patrimonial, etc., ampliando o foco para incluir não só o "historiador consulente", como também o "historiador do outro lado do balcão", ou seja, 0 profissional de história que deverá prestar serviços aos pesquisadores eà comunidade em geral. Com isso, tais disciplinas colaboram, simultaneamente, com a formação dos historiadores pesquisadores, que agora saberão, ao menos em suas linhas gerais, como funcionam as instituições onde buscam suas fontes (tendo a noção, por exemplo, no caso dos arquivos, de que estas fontes não são organizadas por ordem temática, mas em função de sua fonte geradora), e também na 
Os historiadores e os acervos documentais e museológicos...

preparação dos profissionais que poderão trabalhar como funcionários qualificados nestes espaços.

Parece-me, contudo que, para além de cursos de caráter mais técnico (com noções básicas de arquivística ou museologia, por exemplo), e de estágios "de observação" e/ ou "de vivência", o mais importante é exercitar nos estudantes - por meio das mais variadas atividades pedagógicas - a capacidade de voltar para os acervos aquele tipo de olhar que, por dever de ofício, eles já devem lançar aos demais objetos que estudam: um olhar eminentemente histórico, que desnaturaliza os objetos (inclusive os papéis), seus arranjos, combinações, organizações e classificações, mostrando que tais operações, aparentemente desinteressadas, resultam de gestos, de escolhas, de omissões e de silenciamentos determinados pelas lutas sociais e políticas presentes em cada contexto histórico. A final, lembrando as palavras de Jacques Le G off (1990, p. 545), "o documento não é qualquer coisa que fica por conta do passado, é um produto da sociedade que 0 fabricou segundo as relações de forças que aí detinham 0 poder". A ssim, se classificamos os documentos de um arquivo de determinada forma, ou se reunimos e apresentamos tais ou quais objetos em um museu de certa maneira, isso certamente se deve a critérios técnicos, mas estes não são neutros, são políticos, e implicam escolhas e omissões. 0 historiador, do meu ponto de vista, seria aquele profissional mais capacitado para perceber esta historicidade dos acervos, para evidenciar os diferentes "estratos do tempo" neles imbricados - usando livremente a expressão de Kosellek (2001) - e, por isso, sua atuação nos espaços que os abrigam me parece fundamental. A credito que o "conteúdo básico" a ser desenvolvido nos cursos de $\mathrm{H}$ istória que buscam qualificar seus alunos para atuarem em museus, bibliotecas, arquivos, centros de documentação, etc. é esta reflexão sobre as controversas e sempre tensas relações entre história e memória, e sobre a maneira como tais formas de apreensão do passado convergem para a constituição e/ ou fortalecimento de identidades presentes. 
Encontro, em muitas destes espaços, a idéia de que a eles caberia "preservar a memória" de uma nação, de um grupo, de uma comunidade, de uma instituição. $N$ ós, historiadores, sabemos que, mais do que preservar, a memória constrói o passado, que ela 0 inventa, no sentido de conferir-Ihe sentido, que ela monta e remonta, esquece e recalca os vestígios pretéritos. M useus, arquivos e memoriais - como "memórias postiças" - operam neste registro: não preservam, não guardam o passado, eles inventam - no sentido de conferir-Ihe sentido, insisto - o passado escolhido por aquele coletivo - e expressam as relações de poder que o perpassam. $E$ isso, ressalto, não é um "problema", mas diz respeito à própria natureza da memória. Ao contrário de nossa ambição contemporânea, não podemos "lembrar tudo" ou "guardar tudo", e tal assertiva vale tanto para o plano individual como para o plano coletivo. Fazemos escolhas e temos, como historiadores, na medida do possível, que mostrar que tais escolhas - pautadas por critérios técnicos expressos nas tabelas de temporalidade, por exemplo - são políticas, históricas, são opções.

$\mathrm{N}$ este contexto, creio, não cabe ao historiador, ao menos não de maneira prioritária, o papel de "corrigir a memória", apontando seus "erros", suas "falsidades", suas "distorções" (embora possa fazer isso também). Por mais que se aprenda nas aulas de teoria da H istória que é impossível conhecer os "fatos como eles realmente aconteceram", tal tarefa aindaé muito cobrada socialmente dos historiadores, sobretudo fora da academia. Frases como "chamamos o senhor para contar o que realmente aconteceu em tal momento" não raramente são ouvidas quando se contrata um historiador para atuar em um memorial, por exemplo. N este sentido, não podemos esquecer que as fronteiras entre história e memória não são rígidas e que a história, seguidamente, torna-se memória e serve como âncora para identidades individuais e coletivas. Porém, parece-me que a memória tem um compromisso maior com o reforço das identidades (nacionais, étnicas, de gênero, políticas, institucionais, entre 
Os historiadores e os acervos documentais e museológicos...

outras), enquanto que a história deve se voltar à historicização destas identidades, evidenciando-as como construções históricas, e não como essências ou dados naturais - não se trata, repito, de dizer se uma memória ou identidade é falsa ou verdadeira, mas de mostrar que elas (inevitavelmente) são representações, construções imaginárias, resultados de processos de seleção, de inclusão e de exclusão.

O bviamente que reflexões teóricas como as que acima esbocei implicam grandes desafios para a prática profissional do historiador nestes espaços. Q uestionar a fixidez de procedimentos e de "normas técnicas" certamente não é uma posição cômoda. D a mesma forma, quando se é contratado para atuar em um memorial, normalmente a instituição contratante já tem uma determinada imagem sobre si, ancorada em uma certa visão sobre o seu passado, que deseja ver reforçada em uma narrativa histórica coerente, documentada e com a "chancela científica" do historiador. N ão cabe, e peço perdão pela insistência, a este profissional dizer se tal identidade ou tal memória é "falsa" ou "verdadeira", mas sim evidenciar a sua historicidade, o seu caráter de construção histórica, o que implica, como no caso de qualquer construção - inclusive, e principalmente, a narrativa histórica - permanências, mudanças, omissões, seleções e esquecimentos.

M as, tentando ser mais prático, arrisco fazer algumas proposições gerais quanto ao trabalho dos historiadores nestes lugares de memória. A primeira diz respeito à importância de se trabalhar em equipe - que pode incluir arquivistas, museólogos, bibliotecários, arquitetos, jornalistas, designers, advogados, etc. - de forma a permitir que diferentes olhares possam ser lançados ao passado que se deseja narrar, conservar, expor. D izer o que foi não é monopólio dos historiadores - e o sucesso atual dos jornalistas nesse campo está aí para demonstrar isso. A brir-se à discussão e à pluralidade, e também ser capaz de suportar o grau de conflito e de frustração implicado neste diálogo seguidamente tenso entre tantos olhares disciplinares diferentes é, acredito, uma das capacidades a serem 
adquiridas pelo profissional de $\mathrm{H}$ istória que pretende atuar nos novos espaços de atuação acima referidos.

D ecorre desta proposição uma segunda: o historiador deve saber negociar, mas sem abrir mão dos requisitos e dos objetivos mínimos de seu ofício - e o principal, como já ressaltei, é mostrar o sentido de construção de qualquer narrativa sobre o passado, e evidenciar que o conhecimento histórico se baseia no diálogo, no ir e vir, entre as questões do presente e os vestígios do passado. $\mathrm{N}$ este sentido, não é demais citar a bela frase da historiadora $\mathrm{N}$ atalie D avis (1987, p. 21), extraída de seu livro "O retorno de Martin G uerre": "o que aqui ofereço ao leitor é, em parte, uma invenção minha, mas uma invenção construída a partir da escuta atenta das vozes do passado". E ste caráter de invenção - mas uma invenção controlada pelas regras do ofício e balizada pelas fontes - do conhecimento que elaboramos deve ser constantemente lembrado àqueles que contratam nossos serviços, aos responsáveis pelas instituições onde trabalhamos, para que 0 caráter científico deste mesmo conhecimento não sirva de aval para que qualquer invenção apareça como "a verdade".

Q uando tratamos do papel da AN PUH neste novo universo que se abre aos licenciados e bacharéis em $\mathrm{H}$ istória, normalmente nos limitamos à discussão da tão esperada (e tão adiada) regulamentação da profissão do historiador, que acredito fundamental em um mercado de trabalho cada vez mais regulamentado. Sem o reconhecimento oficial de nossa profissão, como podemos, por exemplo, assegurar a presença dos historiadores nestas instituições? Como podemos garantir a realização de concursos específicos? Parece que não há dúvidas sobre a necessidade de haver arquivistas em arquivos, museólogos em museus (até porque suas ausências seriam denunciadas por seus conselhos profissionais), mas, seguidamente, a presença de historiadores em tais espaços é vista apenas como a "cereja do bolo", enão como uma necessidade incontornável. É neste sentido que a regulamentação se torna importante. 
Os historiadores e os acervos documentais e museológicos...

Considero, portanto, fundamental essa luta pela regulamentação da profissão. A final, como ressaltei, vivemos em um mundo regulamentado e trabalhamos lado a lado com profissionais que têm profissão regulamentada, como museólogos e arquivistas. Precisamos assegurar a presença de historiadores profissionais em espaços voltados ao ensino de $\mathrm{H}$ istória, à pesquisa histórica e à preservação do patrimônio histórico-documental. Temos funções e contribuições específicas nestes âmbitos que não podem ser exercidas/ oferecidas por arquivistas, museólogos, jornalistas, entre outros profissionais, da mesma forma que estes não podem ser substituídos pelos historiadores. A regulamentação, em princípio, garantiria nossa presença nestes espaços ou ao menos daria amparo legal a ela, assim como à abertura de concursos específicos e à fiscalização das práticas ligadas ao nosso ofício. Porém, não considero a regulamentação suficiente para legitimar a nossa prática profissional. Há inúmeros outros desafios que não podem ser "varridos para debaixo do tapete" e que não serão resolvidos magicamente por meio de um ato legal. Q ue desafios são estes? Encerro minha apresentação elencando apenas alguns deles:

1) 0 primeiro e mais fundamental: definir com mais precisão as funções dos historiadores nestes novos espaços de atuação profissional. Q uais seriam as particularidades do "ato histórico" (por analogia ao ato médico)? E m equipes multiprofissionais, o que só caberia a nós? Podemos nos reservar a exclusividade de pesquisar e escrever sobre o passado, por exemplo? Como fiscalizar os outros profissionais que se ocupam do passado?

2) Os nossos cursos de graduação têm formado profissionais habilitados a atuar nestes novos espaços? Q ue disciplinas, conteúdos e práticas precisariam ser inseridos nas grades curriculares?

3) Podemos pensar em algo como um código de ética do historiador? Q uais seriam os seus elementos básicos? Como assegurar procedimentos éticos mínimos da parte deste profissional diante dos embates já referidos acima entre a pretensão de reforço da 
memória, da parte dos dirigentes das instituições, por exemplo, e o exercício da análise histórica?

A ssim, acredito que cabe à AN PUH, além de lutar pela regulamentação da profissão, promover a reflexão sobre essas e outras espinhosas questões, abrindo canais de comunicação com a sociedade a fim de demonstrar que não há bons arquivos ou bons museus, ou lugares de memória que não se pretendam apenas celebrativos, sem a presença de historiadores.

$\mathrm{H}$ istorians and document and museum collections: new fields of professional activities

Abstract: This text makes a reflection on the emergence of new professional fields of activities to historians in institutions like museums, archives, memorials and culture centers, by trying to analyze the context where this process - pointed by a spreading "culture of memory" - takes place, as well as the challenges related to this process as for education, professional practice and the role of A N PUH as an entity representative of historians.

Keywords: H istorian profession. Places of memory. AN PUH . Archives. M useums

$\mathrm{N}$ otas

${ }^{1}$ IX Encontro E stadual de H istória - "Vestígios do passado: a H istória e suas fontes". Porto A legre, Campus do Vale/ UF RG S, 14 a 18 de julho de 2008.

\section{Referências}

BO RG E S, Jorge L uis. Funes, o memorioso. In: F icções. Porto A legre: G lobo, 1970. DAVIS, N atalieZ emon. 0 retorno deM artin G uerre Rio deJaneiro: Paz eTerra, 1987. E SSI N G E R, Silvio. A ImanaqueA nos 90. Rio de Janeiro: A gir, 2008.

H ART O G , François. 0 tempo desorientado. Tempo e história. Como escrever a história da França? A nos 90, Porto A legre, n. 7, julho de 1997.

H UYSSE N , A ndreas. Seduz idos pela memória: arquitetura, monumentos, mídia. Rio deJaneiro: A eroplano, 2000. 
Os historiadores e os acervos documentais e museológicos...

K OSE LLE CK, Reinhardt. L os estratos del tiempo: estudios sobrela historia. Barcelona: Paidós, 2001.

LE GOFF, Jacques. D ocumento/ monumento. In: H istória e memória. Campinas: Ed. daUNICAMP, 1990.

N O RA, Pierre. E ntre memória ehistória: a problemática dos lugares. Projeto H istória, (O) São Paulo, n. 10, dezembro de 1993.

Recebido em 25/ 11/ 2008 A provado em 15/ 12/ 2009 